\title{
Dyslexia, a lesson in reading disabilities
}

MARGARET REICH

Senior Staff Editor

Around October, that "new" smell of books begins to fade and notebook pages become dog-eared with use as schoolwork intensifies. It's also a time when students with a reading disability, such as dyslexia, may feel hopelessly left behind in the classroom.

\section{What's in a name?}

When Samuel T. Orton, MD, first wrote about dyslexia in the 1920s, the problem was thought to be primarily a visual one. Since then experts realize dyslexia involves more than one entity. Thus, some professionals prefer the broader term "reading disability."

Whatever the label, dyslexia affects people of normal or above normal intelligence who, despite being exposed to standard educational methods, have difficulty in learning to read or understand what is read. As many as $15 \%$ of American students may be classified as dyslexic.

There is no such thing as a "typical" dyslexic. Some have trouble remembering what was read; others have difficulty spelling or confuse vowel sounds and consonant blends. Dealing with numbers might spell trouble. Writing may be difficult or sloppily done. Mirror writing in which letters are written backwards occurs in some cases. Still others leave out, insert, or replace words while reading. The only thing known for certain about this disability is that dyslexics read at a significantly lower grade level than normal readers of a similar age and intelligence.

\section{What goes wrong?}

Theories abound as to what actually causes this reading disability in otherwise normal, healthy children and adults. A few of these are discussed here.

\section{Neurological}

One example suggests that brain structure and activity may play a role in certain types of dyslexia. The brain is divided into a left and right hemisphere. In most persons, the left hemisphere-responsible for speech, words, and symbols - dominates the right hemisphere. The latter controls nonverbal and perceptual abilities.

Usually, the brain's left side is larger than the right. However, postmortem examination has revealed some dyslexics have a left hemisphere equal in size to the right. Electroencephalographic monitoring has uncovered a poorer quality of brain acitivity in the left hemisphere than the right in some dyslexic children.

\section{Genetic}

Certain researchers think genes may determine whether or not a person is dyslexic. "In many instances of a 'hard core' dyslexic, it runs in families. We have reason to believe it's genetic. Chromosome 15 is probably the culprit," said Jim Kavanagh, PhD, associate director of research of the Center for Research for Mothers and Children, the National Institute of Child Health and Human Development in Bethesda, Md.

Family ties prove strong in this case: Up to $40 \%$ of dyslexic children share the problem with an immediate relative. Males with this disability outnumber females anywhere from $4: 1$ to $10: 1$.

However, these figures may not be that easily explained. "It's hard to sort out whether this is because of genes or whether there's some way of handling learning in the family that gets passed on," suggests Katherine Tyson, PhD, coordinator of the comprehensive child evaluation program at Olympia Fields Osteopathic Medical Center, Olympia.Fields, 
III, and assistant professor of clinical social work at the University of Illinois at Chicago.

"Girls seem to be more verbal earlier than boys. That could be because the educational standards are set up for girls rather than boys, and why more boys seem to be learning disabled," explains Dr. Tyson.

\section{Decoding difficulties}

Many experts agree dyslexia has its roots in lingual deficiencies. It seems dyslexics lack an "inner voice" normal readers have that enables them to recognize and interpret or decode vowel sounds, phonetic consonant blends, and syllables. Without this "inner voice," dyslexics rely on the visual "shape" of words. In a language like English where replacing a single vowel in similar looking words (pat, pet) changes an entire meaning, memorizing every word's shape is impossible. Even if it were possible, memorization does not mean the same as comprehension, which is the ultimate goal of reading.

\section{Psychological}

The child's emotional state plays an important role in any learning disability, including dyslexia. In Dr. Tyson's experience, most often dyslexia is related to family interaction. "The child may come from a family where learning isn't encouraged. A lot of parents of dyslexics say they never liked school."

Emotional family upheavals, such as divorce, complicate the matter, especially if they occur when the child is just learning to read. Sometimes a parent has unrealistically high expectations of the youngster. Unable to meet these standards, the child feels defeated or frustrated.

Family members aren't the only ones who can foster frustration in such a child. Teachers can do the same when they label a student lazy or give up on that youngster. Placing a student in another class in which he or she may be more comfortable alleviates the stress that aggravates the situation.

\section{Diagnosing the problem}

Despite these complexities, dyslexics can be helped, but early diagnosis is crucial. The longer it's delayed, the further behind the adolescent or adult student falls in reading and the more difficult it becomes to make up the disparity.

Adds Dr. Tyson, "By the time they get to be that old, there's almost always real emotional problems because they felt like a failure for so long. Usually they've been deprived of the rewards that most people get from doing well in school and having a sense of vocation. We have to help not only with the remediation for the learning disability, but help them make career choices and get them the educational training needed."

Not surprisingly, a team approach-physicians, psychologists, educators, social workers, and parents - works best to meet the dyslexic's various needs. A medical examination rules out neurological abnormalities (seizures), vision or hearing problems, or other physical defects that may affect reading capabilities.

Determining cognition with an IQ test helps to exclude mental retardation. Likewise, a neuropsychological examination that might test drawing, hand movements, and other motor activities, helps define the child's strengths and weaknesses in his or her learning and thinking capabilities.

Standardized tests given in schools elicit reading and vocabulary levels. Certain tests use nonsense words to tell whether or not a child is "faking" reading, that is relying on the look of words rather than sound.

\section{Developing an educational program}

Based on these findings, as well as parental input, a reading program is tailored for each student. Usually the child receives tutoring one-on-one. While the methods may vary, they frequently rely on building a child's self-esteem. For example, each session might begin with material the child coveredand mastered - the day before and continue from there. Or, sessions may cover subjects in which the child does well or finds interesting. The idea is to get the child to use his or her assets to overcome the learning disability.

Throughout this entire process, parental involvement remains important. From the very beginning, parents need to pay attention to their child's behavior. While every child matures at a different rate, most youngsters show signs of curiosity at about age 5 or 6 . A child with little interest in learning might be dyslexic. Since some behaviors don't show up at home, parents need to keep in touch with their child's teacher. Falling grades may also signal trouble. Don't underestimate a child's abilities. 


\section{Finding help}

When school officials find a child learning disabled, the diagnosis shouldn't end at the classroom door. Local hospitals or universities might have the facilities needed for neurological and psychological examinations. They can help parents locate tutors and refer families to social service agencies for support.

Currently, no simple solution exists for this specific learning disability, but research continues. In the meantime, dyslexics, like Olympic gold medal winner Greg Louganis, prove those who overcome their problem are true champions.

(All material in the Patient Health Guide is reviewed by JAOA physician referees.)

\section{References:}

Developmental dyslexia \& related reading disorders. By James Kavanagh and Grace Yeni-Komshian. US Department of Health and Human Services, National Institutes of Health, Bethesda, MD, 1988.

Dyslexia. By Frank Vellutino. Scientific American, vol 256, pp 34-41, March 1987.

Dyslexia (editorial). By Bennett Shaywitz and Stephen Waxman. The New England Journal of Medicine, vol 316, pp 1268-1270, May 14, 1987.

Dyslexia: Recognizing shapes, not sounds. By Sarah Vandershaf. Psychology Today, vol 21, p 12, March 1987.

Facts about dyslexia. Children Today, vol 14, pp 23-27, Nov-Dec 1985.

Learning disabilities: Update comment on the visual system. By George Beauchamp and Gregory Kosmorsky. Pediatric Clinics of North America, vol 34, pp 1439-1446, Dec 1987.

Mapping the mind. By Joshua Fischman. Psychology Today, vol 19, p 18, Sept 1985.

The Merck Manual of diagnosis and therapy. Edited by Robert Berkow, et al. Ed 15, Merck Sharp \& Dohme Research Laboratories, Rahway, New Jersey, 1987.

New test for dyslexics. Children Today, vol 15, pp 5-6, Sept-Oct 1986. 